Goldschmidt 2021 Abstract

https://doi.org/10.7185/gold2021.7545

\section{Reduction of U(VI)-citrate by whole microbial cells and pure enzymes: what controls $U$ isotope signatures?}

\author{
ASHLEY BROWN ${ }^{1}$, MARGAUX MOLINAS ${ }^{2}$, YVONNE \\ ROEBBERT $^{3}$, ATARU SATO ${ }^{4}$, MINORI ABE ${ }^{4}$, STEFAN \\ WEYER $^{5}$ AND RIZLAN BERNIER-LATMANI ${ }^{1}$ \\ ${ }^{1} \mathrm{EPFL}$ \\ ${ }^{2}$ EPFL ENAC IIE EML \\ ${ }^{3}$ Leibniz University Hannover, Institute for Mineralogy \\ ${ }^{4}$ Tokyo Metropolitan University \\ ${ }^{5}$ Wilhelm Leibniz Universität Hannover, Institut für Mineralogie \\ Presenting Author: ashley.brown@epfl.ch
}

Microbial reduction of $\mathrm{U}(\mathrm{VI})$ is widespread in the environment, both in pristine and engineered environments. Several studies have shown that such enzymatic redox transformations are accompanied by mass-independent isotope fractionation, with enrichment of the heavy U-238 in the U(IV) products, in accordance with nuclear field shift theory. However, fundamental mechanistic information is lacking on the factors that affect the direction and magnitude of the $U$ isotope signature. Recent research has implicated reaction rate as a primary determinant of $U$ isotope fractionation [1], however, the reasons for this are not well established.

To explore this question, reaction kinetics and associated isotope fractionation during $\mathrm{U}(\mathrm{VI})$-citrate reduction by $S$. oneidensis were assessed. U isotope analyses with MC-ICP-MS reveal relatively constant isotope fractionation factors of $\sim 0.5 \%$, irrespective of reaction rates imposed by biomass concentrations. This is far from equilibrium isotope fractionation of $\sim 2 \%$, as determined both experimentally and theoretically, using $a b$ initio calculations. Second, using a mathematical framework first established for microbial sulfur fractionation [2], we will interpret isotope signatures arising from systems in which reaction rates are limited by electron flow from the donor, lactate.

Additionally, cell-free extracts containing redox-active enzymes derived from cultures of $S$. oneidensis were also reacted with U(VI)-citrate to determine the importance of an intact cellular electron-transport system or membrane transport in controlling microbial $\mathrm{U}$ isotope signatures. A fractionation factor of $\sim 1 \%$ o suggests that significant back-reaction is permitted in the absence of whole cells.

Finally, recombinant MtrC [3], a $c$-type cytochrome from $S$. oneidensis with proven $\mathrm{U}(\mathrm{VI})$ reducing capacity, was purified and reacted with $\mathrm{U}(\mathrm{VI})$-citrate. Here, binding extents and $\mathrm{U}(\mathrm{VI}) / \mathrm{U}(\mathrm{IV})$ concentrations for both the protein-bound and aqueous phases have been determined and, for the first time, we will report the $U$ isotope signatures for reduction by a single enzyme, independent from confounding factors such as membrane transport or a cellular boundary layer.

These data contribute toward a comprehensive understanding of the mechanistic controls on uranium reduction and isotope fractionation by microorganisms.

[1] Basu et al. (2020), Environ. Sci. Technol. 54(4), 2295-
2303.

[2] Rees (1973), Geochim. Cosmochim. Acta 37, 1141-1162.

[3] Shi et al. (2006) J. Bacteriol. 188(13), 4705-4714. 